\title{
Reflexões de Hannah Arendt sobre as implicações do perdão na esfera pública
}

Alana de Andrade Santana

\section{Resumo}

Uma das dimensões da condição humana é a ação caracterizada pela imprevisibilidade e pela irreversibilidade. É no poder do perdão que o indivíduo encontra sua redenção. Na obra A condição humana, Hannah Arendt propõe uma concepção diferente de perdão, deslocando-o do âmbito religioso para o campo político. Este estudo objetivou refletir sobre o conceito de perdão de Hannah Arendt e suas implicações nos domínios público e político. Para tanto, duas perguntas são lançadas: o perdão tem uma dimensão política, fora da religiosa? Em caso positivo, quais as suas repercussões nas esferas pública e política? Trata-se de pesquisa qualitativa, com revisão bibliográfica, a partir da obra já referida e de artigos publicados em português. Constatou-se que a autora propõe pensar o perdão como atributo possível e, porque não dizer, fundamental no campo político e das relações humanas, como algo ínsito e indispensável à materialização da "condição humana" do ser humano.

Palavras-chave: Condição Humana - Perdão - Hannah Arendt. 


\section{Introdução}

A ideia do perdão tem sido, ao longo dos séculos, diretamente associada às questões religiosas. A influência do Gristianismo foi decisiva nisso, tendo em vista que a sua prática é largamente difundida pelos ensinamentos de sua principal referência - Jesus de Nazaré.

Graças a isso, falar ou pensar em perdão, enquanto virtude que fomenta o "esquecimento das ofensas", não parecia adequado a uma sociedade que cada vez mais buscava a secularização de suas práticas e de seu pensar, haja vista que o discurso religioso respondeu por severos atentados contra a liberdade de pensar, cerceando o avanço das ciências e da filosofia.

$\mathrm{Na}$ contramão desse sentimento de rejeição, Hannah Arendt (I9o6I975), relevante pensadora alemã e judia do século XX, resgata o perdão desse emaranhado confuso e confundido por uma cultura religiosa e, por vezes, desprovida de reflexão crítica, para emprestar-lhe uma concepção diferente, marcada por uma dimensão social e política, por isso mesmo pública.

Em seu livro A condição humana (2007), a autora se debruça sobre, dentre outros, o problema do perdão, para situá-lo como uma necessidade humana, indispensável para o bem-viver, cuja compreensão não dispensa a atividade crítica do pensar.

Com o objetivo de realizar uma reflexão sobre o conceito de perdão teorizado por Hannah Arendt e suas implicações nos domínios público e político, este trabalho buscará responder a duas perguntas: o perdão tem uma dimensão política, além da religiosa? Em caso positivo, quais as suas repercussões nas esferas pública e política?

Para tanto, por meio de uma análise bibliográfica, com base no livro $A$ condição humana e em outras referências publicadas em português, será apresentada Hannah Arendt e a relevância da sua obra. Em seguida, será feita uma breve análise do livro A condição humana, situando o debate sobre a importância do perdão no contexto político, bem como dos argumentos utilizados pela autora para sustentar sua tese.

Ao final, espera-se constatar a importância do perdão como atributo possível e condição indispensável à preservação da "condição humana" do indivíduo.

\section{As implicações do perdão no pensamento de Hannah Arendt}

Hannah Arendt é uma das principais pensadoras do século XX. O fato de ter sido judia e alemã lhe permitiu ter uma experiência de vida singular, sobre- 
tudo por ter vivido não só durante a Segunda Guerra Mundial, como também por ter sentido pessoalmente os reflexos da perseguição que os alemães nazistas empreenderam contra os judeus.

Nascida em Hanôver em I906, filha da classe média judaica, com influência da cultura alemã, passou a cursar filosofia aos I8 anos, momento que lhe possibilitou conhecer Heidegger, com quem manteve uma relação amorosa "proibida" durante muitos anos. A ascensão do nazismo em I933 a fez deixar a filosofia para engajar-se em um grupo sionista. Presa em função de suas ideias, de seu engajamento social e por ser judia, depois de liberta deixou a Alemanha e fugiu para Paris (DUARTE, 2000).

Em I94I, na condição de apátrida, exilou-se nos EUA por conta da guerra que tomava o continente europeu. A partir daí, sua produção intelectual se volta para a investigação do totalitarismo, na tentativa de compreensão de suas origens e de suas consequências para a humanidade (DUARTE, 2000).

Suas obras estimulam os leitores à atividade reflexiva do pensar, um último mergulho na vida do espírito, trazendo diversos temas contemporâneos, como genocídio, alienação e mesmo o totalitarismo, além do estudo do fenômeno do pensamento. Dentre as mais importantes publicações de Arendt, está o livro A condição humana, cujo tema a autora estuda da Antiguidade à Modernidade, organizando-o também em três aspectos: labor, trabalho e ação.

O primeiro termo, labor, relaciona-se com a fisiologia da vida animal, com as necessidades físicas da natureza animal que impelem o seu representante humano, animal laborans, a laborar para atendê-las, garantindo sua sobrevivência biológica. O segundo termo, trabalho, é entendido como a atividade capaz de transformar a natureza, fabricar e compartilhar novas coisas no mundo. Aqui emerge o representante do ser humano, homo faber, como aquele capaz de agir e modificar a matéria inerte. Já a dimensão da ação é aquela que ocorre somente na presença e na relação entre os indivíduos, ou seja, na vida em sociedade. Para Arendt, a ação é a atividade política, propiciada pela interação e convivência entres os seres humanos, haja vista que a ação é exclusiva da esfera pública, enquanto o labor e o trabalho pertencem à esfera privada.

E qual seria a diferença entre uma esfera e outra? Enquanto na esfera privada o ser humano busca a satisfação de necessidades intrínsecas e individuais, a esfera pública se revela como "um domínio no qual os homens podem transcender suas vidas através da ação, da capacidade de iniciar algo novo" (DIAS, 20I3, p. I37). Surgindo como espaço comum, nela torna-se possível a realização de grandes feitos, de modo que sejam capazes de marcar as gerações vindouras. A esfera pública conduz o indivíduo a "uma existência não mais 
voltada à simples manutenção da vida, mas à tentativa de transcender, por meio de palavras e ações, sua efemeridade no mundo" (DIAS, 20I3, p. I27).

Uma das dimensões da condição humana é, portanto, a ação, caracterizada pela imprevisibilidade e pela irreversibilidade. Quanto a este último aspecto, é no poder do perdão que encontrará sua redenção, assunto em que nos deteremos neste texto.

$\mathrm{O}$ perdão enquanto virtude humana tem sido associado à teoria e à prática religiosa. Na sociedade ocidental, de influência predominantemente cristã, esse conceito se insere no imaginário das pessoas a partir da leitura de textos místicos, a exemplo da Bíblia. Assim, "é normalmente visto como irrealista na esfera pública devido à sua conotação religiosa", como pontua Lafer (I988, p. II4).

Ali, o perdão se insinua como qualidade daqueles que são virtuosos, recomendado pela maior referência do cristianismo - Jesus - como condição daqueles que desejam estar próximos da divindade. Assim, seja quando ensinado na chamada "oração dominical", em que, em um diálogo místico com a divindade, solicita-se o perdão na medida em que se perdoa (Mateus, 6:12); seja na recomendação da necessidade de perdoar não sete, mas setenta vezes sete vezes (Mateus, I8:32), como em outras tantas passagens da Bíblia, o perdão é recomendado como signo de quem se conecta com algo transcendente, espiritual e religioso.

Na obra de Hannah Arendt, o perdão assume uma dimensão diferente. Para o entendermos, faz-se necessário, primeiramente, permear a definição de pluralidade, ação e discurso dada pela autora.

Hannah Arendt traz a ideia da pluralidade humana, com seu duplo aspecto de igualdade e diferença, como condição primordial da ação e do discurso. Para a autora, essa "pluralidade é a paradoxal pluralidade de seres singulares" (ARENDT, 2007, p. I89), pois, na pluralidade, os seres humanos compreendem-se entre si e os seus ancestrais, identificando-se e se reconhecendo entre iguais a conviver em uma comunidade. No entanto, nessa mesma pluralidade há distinções partilhadas com tudo o que vive, tornando-os seres únicos em sua singularidade. Essa distinção existente entre os seres humanos mostra-se na ação e no discurso, pois, nas palavras de Arendt, "através deles, os homens podem distinguir-se, em vez de permanecerem apenas diferentes" (2007, p. I89).

A autora completa, ainda, afirmando que a ação e o discurso são formas pelas quais os indivíduos interagem e se manifestam, evidenciando sua condição humana.

O indivíduo, ao mesmo tempo em que revela sua singularidade por meio de suas palavras e de seus atos, também se insere no mundo humano à seme- 
lhança de um segundo nascimento, "no qual confirmamos e assumimos o fato original do nosso aparecimento físico original" (ARENDT, 2007, p. I89).

Arendt aduz que toda ação é um novo início e cita a filosofia política de Santo Agostinho para trazer a ideia de que os seres humanos são iniciadores, portanto impelidos a agir e iniciar novos processos. Assim, diz Agostinho, "o homem foi criado para que houvesse um começo, e antes dele ninguém existia" (apud ARENDT, 2007, p. I90). Arendt esclarece, ainda, tratar-se de um início diferente do início do mundo, um "início de alguém”, de um iniciador que age evidenciando sua singularidade.

A autora ressalta o caráter de imprevisibilidade inerente a todo início e a toda origem, já que ao começar algo novo, ou seja, sem precedentes, não é possível prever o desenrolar e os resultados que possam advir. Além disso, enfatiza que a ação não tem fim, ou seja, "o processo de único ato pode prolongar-se até que a própria humanidade tenha chegado ao fim" (ARENDT, 2007, p. 245).

A esfera dos negócios humanos, segundo Arendt, consiste na teia de relações presente na convivência entre as pessoas. A revelação do agente singular por meio do discurso e da ação, que acarreta um novo início, atinge e modifica uma teia já existente. Esse iniciar de um novo processo formula a história singular da vida de um recém-chegado, um iniciador, recém-nascido, capaz de afetar, com sua singularidade, a história de vida de todos com quem estabelece contato. Destacamos, aí, duas características fundamentais da ação: a já citada imprevisibilidade e a irreversibilidade, uma vez que, não sendo possível controlar, prever as consequências e nem o desencadeamento das nossas ações, dentro da complexidade das teias de relações, também não é possível desfazer aquilo que já foi iniciado (SILVA, 20II). Arendt esclarece, no trecho a seguir, que não é possível para o indivíduo obter o controle sobre o resultado de sua ação, tendo em vista a fragilidade no processo e o anonimato dos autores:

Embora todos comecem a vida inserindo-se no mundo humano através do discurso e da ação, ninguém é autor ou criador da história de sua própria vida. Em outras palavras, as histórias, resultado da ação e do discurso, revelam um agente, mas esse agente não é autor nem produtor. Alguém a iniciou e dela é o sujeito, na dupla acepção da palavra, mas ninguém é o seu autor. (2007, p. 197)

A angústia de ter que lidar com o ônus da irreversibilidade e da imprevisibilidade da ação faz que o ser indivíduo busque se afastar da esfera dos negócios humanos, embora sempre soubesse dessas implicações do agir: 
Os homens sempre souberam que aquele que age nunca sabe exatamente o que está fazendo; que sempre vem a ser culpado de consequências que jamais desejou ou previu; que, por mais desastrosas e imprevistas que sejam as consequências do seu ato, jamais termina inequivocadamente num único ato ou evento, e que seu verdadeiro significado jamais se revela ao ator, mas somente à visão retrospectiva do historiador, que não participa da ação. (ARENDT, 2007, p. 245)

A imprevisibilidade dos resultados e a irreversibilidade do processo desencadeado pela ação encontram sua redenção na própria potencialidade da ação. Diz-nos a autora que a solução para o problema da irreversibilidade é a faculdade de perdoar, enquanto a solução para o problema da imprevisibilidade - incerteza do futuro - está presente na faculdade de prometer e cumprir promessas.

A autora ressalta a existência de uma relação entre as faculdades de perdoar e de prometer: a primeira servindo para "desfazer" os atos do passado, enquanto a segunda servindo para criar, no futuro (mar de incertezas), "ilhas de segurança" que viabilizam a durabilidade e a continuidade das relações humanas. Embora haja essa relação, a abordagem da faculdade de perdoar é o que se nos apresenta como mais imediato.

O perdão, na concepção de Hannah Arendt, está posto no domínio público e político, no sentido de que depende da pluralidade, ou seja, depende da relação com o outro, da presença do outro (MATE, 20I3, p. 308). A inexistência do perdão "limitaria a nossa capacidade de agir a um único ato do qual jamais nos recuperaríamos" (ARENDT, 2007, p. 249). E qual seria a consequência dessa limitação? A autora explica que nos congelaríamos na posição de vítimas das consequências dessa ação, sem o recurso de iniciar um novo processo (MATE, 20I3, p. 308). Ficaríamos presos aos grilhões da vingança e no revanchismo, negando nossa condição humana e a possibilidade de um novo começo.

O perdão, assim, revelar-se-ia como recurso não apenas de liberdade, mas também de libertação, na medida em que retiraria os indivíduos de uma posição passiva, inativa, que é a posição da vítima diante do seu algoz, a este vinculada e amalgamada pelos laços da desforra. Isto, para Arendt, simbolizaria a negação da condição humana, impedindo o início de um novo processo, que seria a oportunidade da reinvenção, do recomeço.

Qual seria a implicação disso para uma vida pública e política? Certamente, em uma sociedade em que o sentimento de vingança social ocupa o lugar da justiça social, esse sentimento produz uma deterioração axiológica e, consequentemente, das teias de relações humanas. Enquanto seres plurais e 
singulares, o exercício da política por meio da ação ficaria inteiramente comprometido.

$\mathrm{Na}$ atuação política de Nelson Mandela podemos encontrar expressivo exemplo dessas afirmações. Não obstante as injustiças sofridas, os quase 30 anos passados na prisão e as humilhações e torturas a que foi submetido, seu exemplo de coragem e postura pacifista despertou, inclusive, a admiração de Hannah Arendt, que defendeu que o líder africano recebesse o Prêmio Internacional da Fundação Balzan, "dedicado à promoção das mais meritórias iniciativas em favor da humanidade no ano de I963" (LAFER, 2OI3, p. 2). Anos depois, quando já liberto e tendo assumido a liderança da África do Sul, como lembra Celso Lafer, Mandela teve oportunidade de demonstrar a validade de alguns conceitos de Arendt, inclusive o do "perdão como faculdade de lidar com a irreversibilidade do que foi feito" ", expressos na Justiça de Transição na África do Sul (LAFER, 20I3). Nas palavras de Celso Lafer:

Justiça de Transição como o modo pelo qual uma sociedade lida com um passado de repressão assumiu na África do Sul, por inspiração de Mandela, o caminho de uma Comissão da Verdade e Reconciliação. Esta abriu espaço público para o testemunho das vítimas do apartheid, colocou-as num diálogo direto com os seus perpetradores, apontou para a compreensão e não para a vingança, para a reparação e não para a retaliação. Afirmou a indispensabilidade da verdade factual e promoveu, pelo perdão, a reconciliação, criando condições para que ela ocorresse entre brancos e negros num país previamente separado, durante décadas, pela hostilidade e pelo ódio. (20I3, p. 2)

A Comissão da Verdade instituída na África do Sul abriu espaço para a primeira experiência humana de utilizar o perdão como meio para lidar com a irreversibilidade do que já foi feito, do que não pode ser mudado. O perdão, assim, tornou-se um princípio-guia da renovação sul-africana, no processo de redemocratização daquele Estado (LAFER, 20I3).

A atuação majestosa de Nelson Mandela na condução política da África do Sul no pós-apartheid representa um exemplo eloquente do quanto é possível e viável o deslocamento do perdão do âmbito estritamente religioso para o

I Dentre os possíveis sinônimos para a palavra "faculdade", o Dicionário Aurélio apresenta "capacidade", "virtude", "possibilidade". Nesse sentido, o perdão pode ser perfeitamente entendido como faculdade, na medida em que expressa a possibilidade ou a capacidade, que pode ser natural ou adquirida, de lidar com a irreversibilidade do que foi feito. Dicionário Aurélio de Português Online. Disponível em: 〈https://dicionariodoaurelio.com/faculdade>. Acesso em: I5 nov. 2017. 
campo da política. O perdão, antes de ser um ato de caridade, como designado no campo religioso cristão, é um ato de solidariedade humana, sem o qual estaríamos atavicamente presos ao passado (MATE, 20I3, p. 3IO).

Não obstante, Hannah Arendt se refere à figura de Jesus de Nazaré como grande descobridor do papel do perdão na esfera dos negócios humanos, ressaltando como foi crucial para a inserção do perdão no domínio público o fato de Jesus ter defendido que "não é verdade que somente Deus tenha o poder de perdoar", como está no livro de Lucas, capítulo 5, versículos 2I a 42, e "que este poder não deriva de Deus", enfatizando o perdão como capacidade a ser mobilizada pelos indivíduos entre si, "pois só assim poderão também ser perdoados por Deus" (ARENDT, 2007, p. 25I).

Essa leitura do perdão apresenta, como consequência, a implicação do sujeito no processo de perdoar. O ser humano é chamado à responsabilidade humana de exercer o perdão entre seus pares, como ser autônomo e maduro.

Quando perdoamos, assumimos a nossa condição humana e sua fragilidade, imprevisibilidade e irreversibilidade, que são incontroláveis. Com isso, não nos dispomos a desfazer os atos pretéritos - pois isso não é possível -, mas nos ofertamos a possibilidade de recomeçar e iniciar um novo ato.

\section{Considerações finais}

Hannah Arendt apresenta sua leitura do perdão entendido como sentimento vivenciado, uma experiência que não pode ocorrer no isolamento, como um ato solitário, sem a presença dos outros. Enfatiza que a faculdade de perdoar depende da pluralidade, deslocando-a para os domínios público e político.

O perdão tem uma dimensão política para além da perspectiva religiosa. É condição indispensável para que o indivíduo seja capaz de lidar com a irreversibilidade do que já foi feito, daquilo que não pode ser mudado. O caso de Nelson Mandela e da condução da África do Sul no período pós-apartheid revela bem essa possibilidade, na medida em que materializa uma experiência em que o exercício do perdão foi o meio social eficaz para deslocá-lo da esfera religiosa, situando-o no campo da política.

Assim, suas repercussões na esfera pública são perceptíveis, com a pacificação dos possíveis conflitos em decorrência da incapacidade de lidar com o passado e com os ímpetos de vingança, sobretudo porque a esfera pública, como espelho dos sentimentos e das necessidades coletivas, precisa ser preservada em detrimento da esfera privada, que espelha interesses intrínsecos e individuais. 
É a partir do perdão que tanto o ofendido quanto o ofensor são libertados do automatismo do processo da ação e de suas consequências. Logo, rompe-se com a cadeia de vingança e revanchismo para inaugurar-se o novo.

A autora, durante toda a leitura da obra A condição humana, estimula-nos à atividade reflexiva do pensamento, ilustrando a possibilidade de pensar o perdão como atributo possível, e porque não dizer fundamental, no campo do político e das relações. Assim, leva-nos a concluir que essa faculdade é vital para a continuidade e manutenção das teias de relações humanas.

\section{Referências}

ARENDT, H. A condição humana. Tradução de Roberto Raposo. IO. ed. Rio de Janeiro: Forense Universitária, 2007.

DIAS, L. B. Características e declínio da esfera pública segundo Hannah Arendt. Polymatheia, Fortaleza, v. 6, n. 9, p. 127-138, 2013.

DUARTE, A. O pensamento à sombra da ruptura: política e filosofia em Hannah Arendt. São Paulo: Paz e Terra, 2000.

LAFER, C. A reconstrução dos direitos humanos: um diálogo com o pensamento de Hannah Arendt. São Paulo: Companhia das Letras, I988.

Mandela, Hannah Arendt e o perdão. Valor Econômico, São Paulo, 6 dez. 2013, p. Ai3. Disponível em: <https://bit.ly/2vQGwTZ>. Acesso em: I6 nov. 2017.

MATE, S. Conceito de perdão em Hannah Arendt. In: MÜLLER, Maria Cristina (Org.). Encontro Hannah Arendt: por amor ao mundo, 7., 2013, Londrina. Anais... Londrina: UEL, 2013. p. 304-313. Disponível em: <https://bit. ly/2OjQcP6>. Acesso em: 2 mar. 2017.

SILVA, M. R. O homem e a política em A condição humana. Estudos Filosóficos, São João del-Rei, n. 6, p. I-I8, 20II. Disponível em: 〈https://bit.ly/2Ok9zaA〉. Acesso em: 2 mar. 2017.

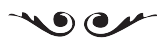

Alana de Andrade Santana é graduanda em Filosofia pela Universidade Federal da Bahia.

alana.deas@gmail.com 